\title{
A new procedure for computing the factor of safety using the Morgenstern-Price method
}

\author{
D.Y. Zhu, C.F. Lee, Q.H. Qian, Z.S. Zou, and F. Sun
}

\begin{abstract}
By employing the same assumption regarding interslice forces as that used in the Morgenstern-Price method, two concise recurrence relations between interslice forces and interslice moments are derived which satisfy both force and moment equilibrium conditions. The Newton-Raphson method is used for determining the factor of safety and the associated scaling parameter of the interslice force function. Algebraic derivatives required in the solution process are evolved in a recursive manner which can be easily implemented in a computer program. The choices of initial values of safety factor and scaling parameter are suggested. The procedure proposed in this paper proves to be efficient and solutions converge rapidly.
\end{abstract}

Key words: slope. stability, factor of safety, limit equilibrium method.

Résumé : En utilisant les mêmes hypothèses concernant les forces intertranches que celles utilisées dans la méthode de Morgenstern-Price, on dérive deux relations concises de répétitions entre les forces intertranches et entre les moments intertranches qui satisfont les conditions d’équilibre tant des forces que des moments. La méthode Newton-Raphson est utilisée pour déterminer le coefficient de sécurité et le paramètre d'échelle associé de la fonction de force entre les tranches. Les dérivées algébriques requises dans le processus de solution sont développées de façon récursive, ce qui peut être facilement exécuté par un programme d'ordinateur. On suggère les choix des valeurs initiales du coefficient de sécurité et du paramètre d'échelle. La procédure proposée dans cet article se montre efficiente et les solutions convergent rapidement.

Mots clés : pente, stabilité, coefficient de stabilité, méthode d’équilibre limite.

[Traduit par la Rédaction]

\section{Introduction}

The limit equilibrium method of slices has been widely used for slope-stability analysis in engineering practice. For a general-shaped slip surface, rigorous limit equilibrium methods of slices are recommended for stability analysis because they satisfy both force and moment equilibrium (Duncan 1996). In practice, the Morgenstern-Price method (Morgenstern and Price 1965) is the most popular of such methods. It adopts a simple assumption regarding the interslice force inclination and involves the least numerical difficulty. The Spencer method (Spencer 1967, 1973) is one special case of the Morgenstern-Price method, since it assumes parallel interslice force inclinations. The Morgenstern-Price method assumes that the inclinations of

Received April 10, 2000. Accepted December 7, 2000.

Published on the NRC Research Press Web site at

http://cgj.nrc.ca on August 21. 2001.

D.Y. Zhu. College of Civil Engineering, Hohai University. Nanjing 210098, People's Republic of China.

C.F. Lee. ${ }^{1}$ Department of Civil Engineering, University of Hong Kong, Hong Kong, China.

Q.H. Qian and Z.S. Zou. Department of Civil Engineering, Nanjing Engineering Institute, Nanjing 210007, People's Republic of China.

F. Sun. Nanjing Hydraulic Research Institute, Nanjing

210024, People's Republic of China.

'Corresponding author (e-mail: leecf@hkucc.hku.hk). interslice forces may be described by a function $\lambda f(x)$, where $\lambda$ is a scaling parameter and $f(x)$ reflects its shape. With this assumption, several authors have derived various forms of force and moment equilibrium equations and developed different schemes for solving the resultant simultaneous equations which involve two unknowns: $\lambda$ and the factor of safety $F_{\mathrm{s}}$. Morgenstern and Price (1965) derived the force equilibrium equation in a differential form and the moment equilibrium equation in an integral form. They then proposed a numerical technique to solve the force and moment equilibrium equations by means of the Newton-Raphson approach (Morgenstern and Price 1967). Spencer (1973) derived a recurrence relationship between the interslice forces and gave the moment equilibrium equation for the whole sliding mass in an algebraic form. He then solved for $\lambda$ and $F_{\mathrm{s}}$ by repeatedly adjusting their values to satisfy the two equations in turn. Fredlund and Krahn (1977) expressed the factor of safety with two implicit equations, one for the force equilibrium and one for the moment equilibrium about a specified point. Assuming a series of values of $\lambda$ and computing the associated values of factor of safety with the two equations, respectively, one can obtain two curves of $F$ versus $\lambda$. The values of $F$ and $\lambda$ at the intersection point of the two curves are thus determined, simultaneously satisfying both force and moment equilibria. Chen and Morgenstern (1983) derived two integral equations satisfying force and moment equilibria, respectively, and solving these equations by means of the Newton-Raphson approach. The derivatives in this case are of an analytic nature but in a complex 
Fig. 1. Sliding mass dividing into slices and forces acting on a typical slice: $(a)$ sliding mass; $(b)$ forces on a slice; $(c)$ forces on a weightless slice.

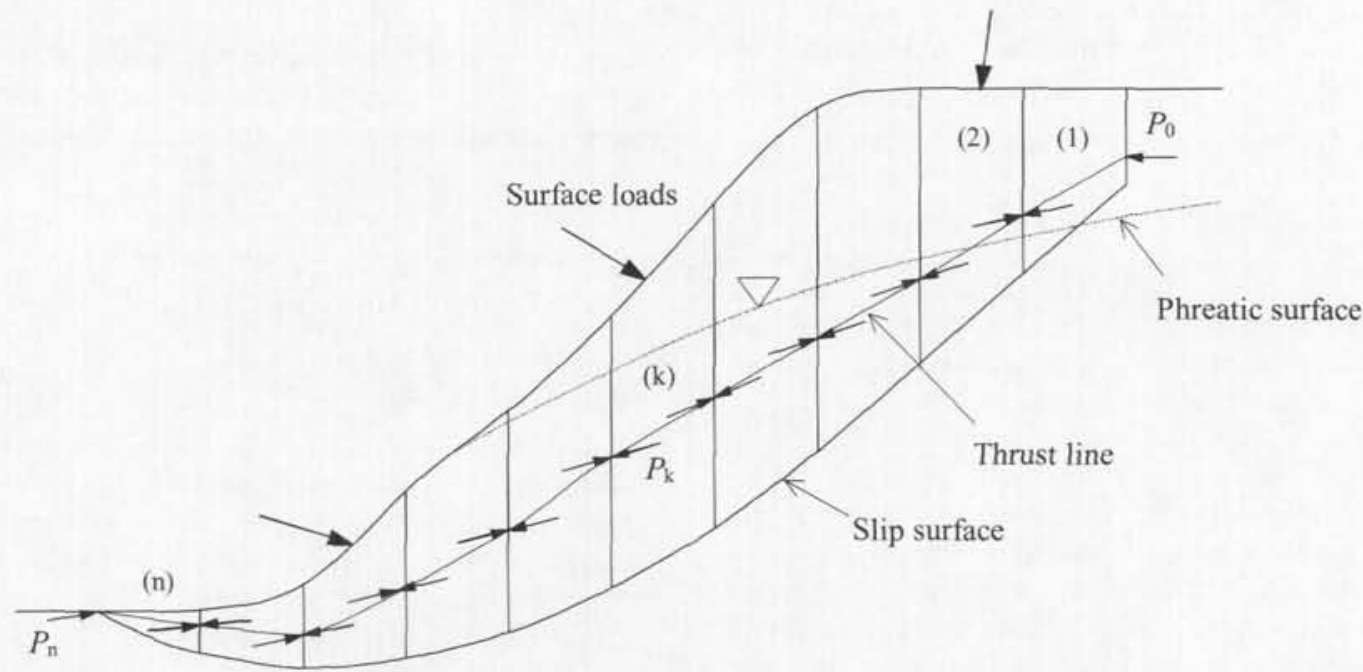

(a)

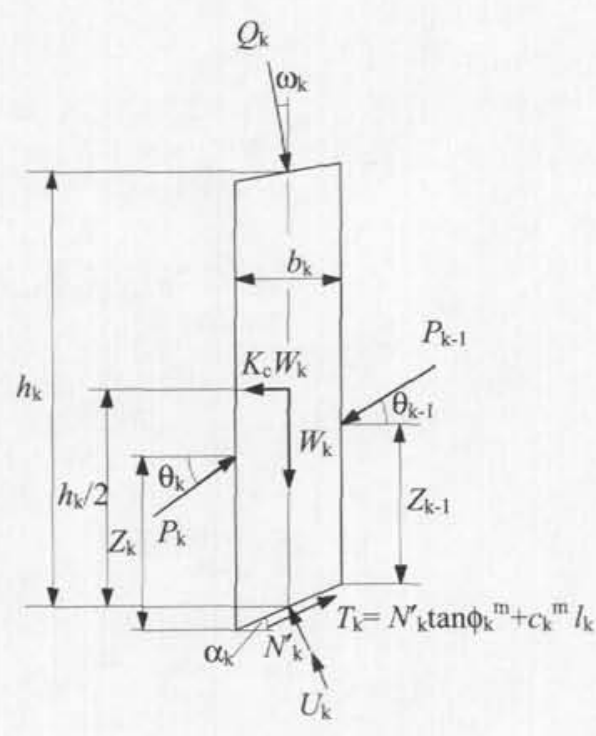

(b)

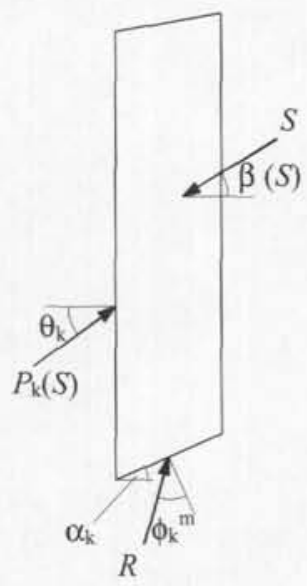

(c) integral form with the integrand in a differential form. Despite these efforts, the Morgenstern-Price method is still rather complicated for some general practitioners, who prefer to use simple methods of slices such as the simplified Janbu method (Janbu et al. 1956), the Lowe and Karafiath method (Lowe and Karafiath 1960), or the U.S. Army Corps of Engineers method (U.S. Army Corps of Engineers 1967), which satisfy only the force equilibrium condition. This paper presents a new concise formulation of force and moment equilibria equations within the framework of the Morgenstern-Price method, with an efficient procedure for computing the factor of safety.

\section{Recurrence relations for interslice forces and moments}

Consider a slip surface of general shape, as shown in Fig. $1 a$, above which the sliding mass is divided into $n$ verti- cal slices. The inclinations and locations of the interslice forces are also depicted in the figure. Now choose a typical slice $k$ for examining the forces acting upon it (Fig. 1b). It should be noted that effective stress is considered in this paper, but the approach is certainly applicable also to total stress.

There are seven sets of forces acting on the slice $k$, as indicated in Fig. $1 b$ : (i) $W_{k}$ is the total weight of the slice; (ii) $K_{\mathrm{c}} W_{k}$ is the inertial force due to an earthquake, where $K_{\mathrm{c}}$ is the coefficient of seismic force which is assumed to be horizontal; (iii) $Q_{k}$ is the surface load acting on the slope surface at angle $\omega_{k}$ to the vertical (positive as indicated in the figure); (iv) $P_{k-1}$ and $P_{k}$ are interslice forces acting on two sides at angles $\theta_{k-1}$ and $\theta_{k}$ to the horizontal, respectively, their locations being at heights $Z_{k-1}$ and $Z_{k}$ above the slice base, respectively; $(v) U_{k}$ is the resultant water force at the slice base ( $U_{k}=u_{k} l_{k}$, where $u_{k}$ is the average pore-water pressure at the base, and $I_{k}$ is the length of the slice base); (vi) $N_{k}^{\prime}$ is the 
effective normal force on the slice base; and (vii) $T_{k}$ is the shearing resistant force at the slice base, assuming the soil obeys the Mohr-Coulomb failure criterion $\left(T_{k}=N_{k}^{\prime} \tan \phi_{k}^{\mathrm{m}}+\right.$ $c_{k}^{\mathrm{m}} l_{k}$, where $\phi_{k}^{\mathrm{m}}$ and $c_{k}^{\mathrm{m}}$ are the mobilized friction angle and cohesion, respectively).

$$
\phi_{k}^{\mathrm{m}}=\tan ^{-1}\left(\frac{\tan \phi_{k}}{F_{s}}\right) \quad c_{k}^{\mathrm{m}}=\frac{c_{k}}{F_{\mathrm{s}}}
$$

where $\phi_{k}$ and $c_{k}$ are the internal angle of friction and cohesion of the slice base, respectively. The other geometrical quantities for the slice are the average slice height $h_{k}$, the slice width $b_{k}$, and the inclination angle of the base $\alpha_{k}$.

Take a weightless slice (the weight being regarded as an external load at its center of gravity) with the same dimension as slice $k$ for examining the recurrence relation between the forces acting on the slice, as shown in Fig. 1c. It is assumed that the slice base only has a friction angle $\phi_{k}^{\mathrm{m}}$, since the shearing force due to cohesion is regarded as an external force. Also assume a force, $S$, acting on the weightless slice at an angle $\beta(S)$ to the horizontal, and the resistant force, $R$, which acts on the base at an angle $\phi_{k}^{m}$ to the normal. The counterpart of force $S$ is $P_{k}(S)$, making an angle $\theta_{k}$ with the horizontal. By resolving the forces $S$ and $P_{k}(S)$ in the direction normal to force $R$, the relation between $S$ and $P_{k}(S)$ is derived as follows:

$$
P_{k}(S)=\frac{\cos \left[\alpha_{k}-\beta(S)-\phi_{k}^{\mathrm{m}}\right]}{\cos \left(\alpha_{k}-\theta_{k}-\phi_{k}^{\mathrm{m}}\right)} S
$$

Note the inclinations of relevant forces in the following:

$$
\begin{array}{ll}
\beta\left(P_{k-1}\right)=\theta_{k-1} & \beta\left(W_{k}\right)=\frac{\pi}{2} \\
\beta\left(K_{c} W_{k}\right)=0 & \beta\left(Q_{k}\right)=\frac{\pi}{2}+\omega_{k} \\
\beta\left(U_{k}\right)=-\left(\pi-\alpha_{k}\right) & \beta\left(c_{k}^{\mathrm{m}} l_{k}\right)=-\left(\pi-\alpha_{k}\right)
\end{array}
$$

The contributions of these forces to the interslice force $P_{i}$ can be determined by using eq. [2]. Summation of their contributions leads to a recurrence relation between the interslice forces for the slice shown in Fig. $1 b$ :

$$
\begin{aligned}
P_{k}= & \frac{1}{\cos \left(\alpha_{k}-\theta_{k}-\phi_{k}^{\mathrm{m}}\right)}\left[\cos \left(\alpha_{k}-\theta_{k-1}-\phi_{k}^{\mathrm{m}}\right) P_{k-1}\right. \\
& \quad+\sin \left(\alpha_{k}-\phi_{k}^{\mathrm{m}}\right) W_{k}+\cos \left(\alpha_{k}-\phi_{k}^{\mathrm{m}}\right) K_{\mathrm{c}} W_{k} \\
& \left.+\sin \left(\alpha_{k}-\omega_{k}-\phi_{k}^{\mathrm{m}}\right) Q_{k}+\sin \phi_{k}^{\mathrm{m}} U_{k}-c_{k}^{\mathrm{m}} l_{k} \cos \phi_{k}^{\mathrm{m}}\right]
\end{aligned}
$$

By taking moments of forces about the midpoint of the slice base, we obtain the following moment equilibrium condition:

$$
\begin{array}{r}
P_{k-1} \cos \theta_{k-1}\left(Z_{k-1}+\frac{b_{k}}{2} \tan \alpha_{k}\right)-P_{k-1} \sin \theta_{k-1} \frac{b_{k}}{2} \\
-P_{k} \cos \theta_{k}\left(Z_{k}-\frac{b_{k}}{2} \tan \alpha_{k}\right)-P_{k} \sin \theta_{k} \frac{b_{k}}{2} \\
+K_{c} W_{k} \frac{h_{k}}{2}-Q_{k} \sin \omega_{k} h_{k}=0
\end{array}
$$

Let

$$
M_{k}=P_{k} \cos \theta_{k} Z_{k} \quad \text { and } \quad M_{k-1}=P_{k-1} \cos \theta_{k-1} Z_{k-1}
$$

where $M_{k}$ and $M_{k-1}$ are known as interslice moments. Substituting eq. [5] into eq. [4] and rearranging, we obtain a recurrence relation between the interslice moments as follows:

$$
\begin{array}{r}
M_{k}=M_{k-1} \\
+\frac{b_{k}}{2 \cos \alpha_{k}}\left[\sin \left(\alpha_{k}-\theta_{k}\right) P_{k}+\sin \left(\alpha_{k}-\theta_{k-1}\right) P_{k-1}\right] \\
\quad+K_{c} W_{k} \frac{h_{k}}{2}-Q_{k} \sin \omega_{k} h_{k}
\end{array}
$$

With known values of $P_{0}$ and $M_{0}$ at the upper end of the sliding mass, the subsequent interslice forces and moments can be computed by using eqs. [3] and [6], respectively, in a recursive manner. Obviously, for overall equilibrium of the sliding mass, the last interslice force and moment must be equal to zero, that is,

[7a] $\quad P_{n}\left(F_{\mathrm{s}}, \lambda\right)=0$

[7b] $\quad M_{n}\left(F_{s}, \lambda\right)=0$

The scaling parameter $\lambda$ and the factor of safety $F_{\mathrm{s}}$ can be determined by solving eqs. $[7 a]$ and $[7 b]$ simultaneously. This will be discussed in the next section.

\section{Solving for $\boldsymbol{F}_{\mathrm{s}}$ and $\lambda$ by the Newton-Raphson method}

The scaling parameter $\lambda$ and the factor of safety $F_{s}$ are contained implicitly in eqs. [7a] and [7b], which are nonlinear in nature. Thus, an iterative procedure is required for their solution. The Newton-Raphson method is often used for solving nonlinear equations. Suppose that the values of $F_{\mathrm{s}}$ and $\lambda$ at the $i$ th step are obtained as $F_{\mathrm{s}}^{(i)}$ and $\lambda^{(i)}$, then their values at the $i$ th step are modified as

$$
\begin{aligned}
& F_{\mathrm{s}}^{(i+1)}=F_{\mathrm{s}}^{(i)}+\Delta F_{\mathrm{s}} \quad \lambda^{(i+1)}=\lambda^{(i)}+\Delta \lambda \\
& \Delta F_{\mathrm{s}}=\frac{P_{n} \frac{\partial M_{n}}{\partial \lambda}-M_{n} \frac{\partial P_{n}}{\partial \lambda}}{\frac{\partial P_{n}}{\partial \lambda} \frac{\partial M_{n}}{\partial F_{\mathrm{s}}}-\frac{\partial P_{n}}{\partial F_{\mathrm{s}}} \frac{\partial P_{n}}{\partial \lambda}} \\
& \Delta \lambda=\frac{-P_{n} \frac{\partial M_{n}}{\partial F_{\mathrm{s}}}+M_{n} \frac{\partial P_{n}}{\partial F_{\mathrm{s}}}}{\frac{\partial M_{n}}{\partial \lambda}-\frac{\partial P_{n}}{\partial F_{\mathrm{s}}} \frac{\partial P_{n}}{\partial \lambda}}
\end{aligned}
$$

The function of the inclination of interslice force is written as

$$
\text { [10] } \tan \theta=\lambda f\left(x^{\prime}\right)
$$

where $x^{\prime}$ is the linearly normalized $x$ coordinate with values at the two ends of the slip surface equal to zero and unity, respectively, and $f\left(x^{\prime}\right)$ is assumed.

Now first differentiate $\phi_{k}^{\mathrm{m}}$ and $c_{k}^{\mathrm{m}}$ with respect to $F_{s}$ and $\theta_{k}$ with respect to $\lambda$ : 
$[11 a] \quad \phi_{k}^{\mathrm{m}}=\tan ^{-1}\left(\frac{\tan \phi_{k}}{F_{\mathrm{s}}}\right) \quad \frac{\mathrm{d} \phi_{k}^{\mathrm{m}}}{\mathrm{d} F_{\mathrm{s}}}=-\frac{1}{2 F_{\mathrm{s}}} \sin 2 \phi_{k}^{\mathrm{m}}$

[11b] $\quad c_{k}^{\mathrm{m}}=\frac{c_{k}}{F_{\mathrm{s}}} \quad \frac{\mathrm{d} c_{k}^{\mathrm{m}}}{\mathrm{d} F_{\mathrm{s}}}=-\frac{c_{k}^{\mathrm{m}}}{F_{\mathrm{s}}}$

[11c] $\theta_{k}=\tan ^{-1}\left(\lambda f_{k}\right) \quad \frac{\mathrm{d} \theta_{k}}{\mathrm{~d} \lambda}=\cos ^{2} \theta_{k} f_{k}$

where $f_{k}$ denotes the value of the interslice force function $f\left(x^{\prime}\right)$ corresponding to the interface between slice $k$ and slice $k+1$.

Let

$$
P_{k}=\frac{A_{k}}{D_{k}}
$$

in which

$$
D_{k}=\cos \left(\alpha_{k}-\theta_{k}-\phi_{k}^{m}\right)
$$

and

$$
\begin{array}{r}
A_{k}=\cos \left(\alpha_{k}-\theta_{k-1}-\phi_{k}^{\mathrm{m}}\right) P_{k-1}+\sin \left(\alpha_{k}-\phi_{k}^{\mathrm{m}}\right) W_{k} \\
+\cos \left(\alpha_{k}-\phi_{k}^{\mathrm{m}}\right) K_{\mathrm{c}} W_{k}+\sin \left(\alpha_{k}-\omega_{k}-\phi_{k}^{\mathrm{m}}\right) Q_{k} \\
+\sin \phi_{k}^{\mathrm{m}} U_{k}-c_{k}^{\mathrm{m}} l_{k} \cos \phi_{k}^{\mathrm{m}}
\end{array}
$$

From eq. [12] the following relations hold:

$$
\begin{aligned}
& \frac{\partial P_{k}}{\partial F_{\mathrm{s}}}=\frac{1}{D_{k}}\left(\frac{\partial A_{k}}{\partial F_{\mathrm{s}}}-P_{k} \frac{\partial D_{k}}{\partial F_{\mathrm{s}}}\right) \\
& \frac{\partial P_{k}}{\partial \lambda}=\frac{1}{D_{k}}\left(\frac{\partial A_{k}}{\partial \lambda}-P_{k} \frac{\partial D_{k}}{\partial \lambda}\right)
\end{aligned}
$$

The derivatives in the above equation are derived as follows:

[16a] $\frac{\partial D_{k}}{\partial F_{\mathrm{s}}}=\sin \left(\alpha_{k}-\theta_{k}-\phi_{k}^{\mathrm{m}}\right) \frac{\mathrm{d} \phi_{k}^{\mathrm{m}}}{\mathrm{d} F_{\mathrm{s}}}$

$[16 b]$

$$
\frac{\partial D_{k}}{\partial \lambda}=\sin \left(\alpha_{k}-\theta_{k}-\phi_{k}^{m}\right) \frac{d \theta_{k}}{d \lambda}
$$

[16c]

$$
\begin{aligned}
& \frac{\partial A_{k}}{\partial F_{\mathrm{s}}}= \cos \left(\alpha_{k}-\theta_{k-1}-\phi_{k}^{\mathrm{m}}\right) \frac{\partial P_{k-1}}{\partial F_{\mathrm{s}}} \\
&+\sin \left(\alpha_{k}-\theta_{k-1}-\phi_{k}^{\mathrm{m}}\right) P_{k-1} \frac{\mathrm{d} \phi_{k}^{\mathrm{m}}}{\mathrm{d} F_{\mathrm{s}}}+\left[-\cos \left(\alpha_{k}-\phi_{k}^{\mathrm{m}}\right) W_{k}\right. \\
&+\sin \left(\alpha_{k}-\phi_{k}^{\mathrm{m}}\right) K_{c} W_{k}-\cos \left(\alpha_{k}-\omega_{k}-\phi_{k}^{\mathrm{m}}\right) Q_{k} \\
&\left.+\cos \phi_{k}^{\mathrm{m}} U_{k}+c_{k}^{\mathrm{m}} l_{k} \sin \phi_{k}^{\mathrm{m}}\right] \frac{\mathrm{d} \phi_{k}^{\mathrm{m}}}{\mathrm{d} F_{\mathrm{s}}}-l_{k} \cos \phi_{k}^{\mathrm{m}} \frac{\mathrm{d} c_{k}^{\mathrm{m}}}{\mathrm{d} F_{\mathrm{s}}}
\end{aligned}
$$

$[16 d] \frac{\partial A_{k}}{\partial \lambda}=\cos \left(\alpha_{k}-\theta_{k-1}-\phi_{k}^{m}\right) \frac{\partial P_{k-1}}{\partial \lambda}$

$$
+\sin \left(\alpha_{k}-\theta_{k-1}-\phi_{k}^{m}\right) P_{k-1} \frac{d \theta_{k-1}}{d \lambda}
$$

Substituting eqs. $[11 a]-[11 c]$ into eq. $[15]$ and then into eqs. $[16 a]-[16 d]$, we have

$$
\begin{aligned}
\frac{\partial P_{k}}{\partial F_{\mathrm{s}}}= & \frac{\cos \left(\alpha_{k}-\theta_{k-1}-\phi_{k}^{\mathrm{m}}\right)}{\cos \left(\alpha_{k}-\theta_{k}-\phi_{k}^{\mathrm{m}}\right)} \frac{\partial P_{k-1}}{\partial F_{\mathrm{s}}} \\
& +\frac{\sin 2 \phi_{k}^{\mathrm{m}}}{2 F_{\mathrm{s}}} \tan \left(\alpha_{k}-\theta_{k}-\phi_{k}^{\mathrm{m}}\right) P_{k} \\
& -\frac{\sin 2 \phi_{k}^{\mathrm{m}}}{2 F_{\mathrm{s}}} \frac{\sin \left(\alpha_{k}-\theta_{k-1}-\phi_{k}^{\mathrm{m}}\right)}{\cos \left(\alpha_{k}-\theta_{k}-\phi_{k}^{\mathrm{m}}\right)} P_{k-1} \\
& +\frac{\sin 2 \phi_{k}^{\mathrm{m}}}{2 F_{\mathrm{s}} \cos \left(\alpha_{k}-\theta_{k}-\phi_{k}^{\mathrm{m}}\right)}\left[\cos \left(\alpha_{k}-\phi_{k}^{\mathrm{m}}\right) W_{k}\right. \\
& -\sin \left(\alpha_{k}-\phi_{k}^{\mathrm{m}}\right) K_{\mathrm{c}} W_{k}+\cos \left(\alpha_{k}-\omega_{k}-\phi_{k}^{\mathrm{m}}\right) Q_{k} \\
& \left.\quad-\cos \phi_{k}^{\mathrm{m}} U_{k}+\cos \phi_{k}^{\mathrm{m}} \cot \phi_{k}^{\mathrm{m}} c_{k}^{\mathrm{m}} l_{k}\right]
\end{aligned}
$$

$$
\begin{aligned}
\frac{\partial P_{k}}{\partial \lambda}= & \frac{\cos \left(\alpha_{k}-\theta_{k-1}-\phi_{k}^{\mathrm{m}}\right)}{\cos \left(\alpha_{k}-\theta_{k}-\phi_{k}^{\mathrm{m}}\right)} \frac{\partial P_{k-1}}{\partial \lambda} \\
& \tan \left(\alpha_{k}-\theta_{k}-\phi_{k}^{\mathrm{m}}\right) \cos ^{2} \theta_{k-1} f_{k} P_{k} \\
& +\frac{\sin \left(\alpha_{k}-\theta_{k-1}-\phi_{k}^{\mathrm{m}}\right) \cos ^{2} \theta_{k-1} f_{k-1}}{\cos \left(\alpha_{k}-\theta_{k}-\phi_{k}^{\mathrm{m}}\right)} \\
\frac{\partial M_{k}}{\partial F_{\mathrm{s}}}= & \frac{\partial M_{k-1}}{\partial F_{\mathrm{s}}}+\frac{b_{k} \sin \left(\alpha_{k}-\theta_{k}\right)}{2 \cos \alpha_{k}} \frac{\partial P_{k}}{\partial F_{\mathrm{s}}} \\
& +\frac{b_{k} \sin \left(\alpha_{k}-\theta_{k-1}\right)}{2 \cos \alpha_{k}} \frac{\partial P_{k-1}}{\partial F_{\mathrm{s}}}
\end{aligned}
$$

$$
\begin{aligned}
\frac{\partial M_{k}}{\partial \lambda}= & \frac{\partial M_{k-1}}{\partial \lambda}+\frac{b_{k} \sin \left(\alpha_{k}-\theta_{k}\right)}{2 \cos \alpha_{k}} \frac{\partial P_{k}}{\partial \lambda} \\
& +\frac{b_{k} \sin \left(\alpha_{k}-\theta_{k-1}\right)}{2 \cos \alpha_{k}} \frac{\partial P_{k-1}}{\partial \lambda} \\
& -\frac{b_{k} \cos \left(\alpha_{k}-\theta_{k}\right) \cos ^{2} \theta_{k} f_{k}}{2 \cos \alpha_{k}} P_{k} \\
& +\frac{b_{k} \cos \left(\alpha_{k}-\theta_{k-1}\right) \cos ^{2} \theta_{k-1} f_{k-1}}{2 \cos \alpha_{k}} P_{k-1}
\end{aligned}
$$

Equations [17]-[20] are the recurrence equations for computing the required derivatives. These equations are in algebraic form involving no numerical approximation and the derivatives in eq. [9] can be exactly computed.

\section{Choices of initial values of $\boldsymbol{F}_{\mathrm{s}}$ and $\lambda$}

The initial values of $F_{\mathrm{s}}$ and $\lambda$ have a considerable effect on the convergence rate. In the extreme, if they are unreasonably assumed, $F_{\mathrm{s}}$ and $\lambda$ may possibly diverge in the iteration process. The following suggested scheme can be used to avoid this difficulty in calculating the factor of safety by the Morgenstern-Price method. The solutions can be obtained in two stages.

At the first stage, the initial value of $F_{\mathrm{s}}$ can be set at unity in all cases and $\lambda$ is assumed equal to a fixed empirical value:

$$
\lambda=0.7 \tan \beta
$$

in which $\beta$ is the inclination of the chord connecting the two ends of the slip surface. With this initial value of $F_{\mathrm{s}}$ and the 
Table 1. Iteration process for computing the factor of safety in example 1.

\begin{tabular}{|c|c|c|c|c|c|c|c|c|c|}
\hline \multicolumn{5}{|c|}{$f\left(x^{\prime}\right)=1$} & \multicolumn{5}{|c|}{$f\left(x^{\prime}\right)=\sin \left(x^{\prime}\right)$} \\
\hline$F_{s}$ & $\lambda$ & $P_{n}(\mathrm{kN})$ & $\Delta F_{\mathrm{s}}$ & $M_{n}(\mathrm{kN} \cdot \mathrm{m})$ & $F_{\mathrm{s}}$ & $\lambda$ & $P_{n}(\mathrm{kN})$ & $\Delta F_{\mathrm{s}}$ & $M_{n}(\mathrm{kN} \cdot \mathrm{m})$ \\
\hline \multicolumn{10}{|c|}{ Compute initial value of $F_{s}$} \\
\hline 1.0000 & 0.2293 & -1546.3 & 0.3992 & & 1.0000 & 0.2293 & -1211.0 & 0.3912 & \\
\hline 1.3992 & 0.2293 & -439.2 & 0.2207 & & 1.3912 & 0.2293 & -316.7 & 0.1874 & \\
\hline 1.6199 & 0.2293 & -58.9 & 0.0395 & & 1.5786 & 0.2293 & -35.1 & 0.0262 & \\
\hline \multicolumn{10}{|c|}{ Compute converged values of $F_{s}$ and $\lambda$} \\
\hline 1.6594 & 0.2293 & -1.4 & & -599.3 & 1.6048 & 0.2293 & -0.5 & & -1741.8 \\
\hline 1.6744 & 0.2553 & -11.7 & & -54.4 & 1.6496 & 0.3355 & -11.7 & & -57.5 \\
\hline 1.6829 & 0.2556 & -0.3 & & -1.2 & 1.6600 & 0.3361 & -0.3 & & -1.7 \\
\hline 1.6830 & 0.2556 & -0.004 & & -0.02 & 1.6602 & 0.3361 & -0.01 & & -0.08 \\
\hline
\end{tabular}

Fig. 2. Slope used in example 1.

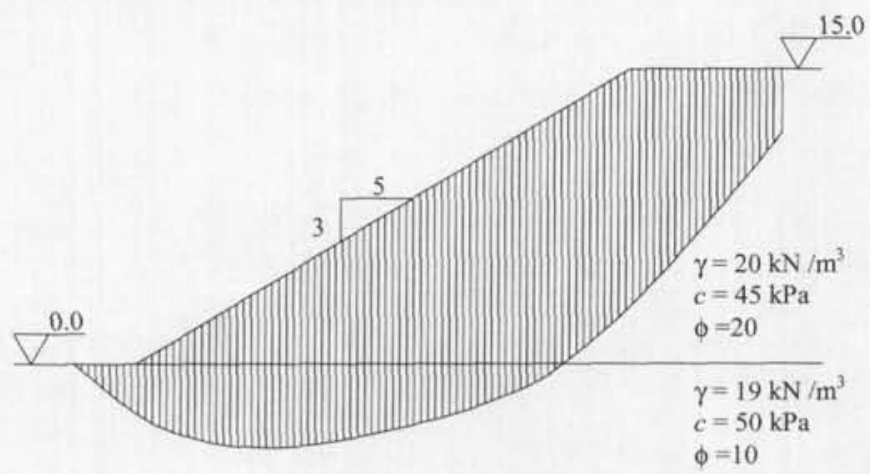

fixed value of $\lambda$ the Newton-Raphson method is used for improving $F_{s}$. The increment in $F_{s}$ for each step is

$$
\Delta F_{\mathrm{s}}=-\frac{P_{n}}{\frac{\partial P_{n}}{\partial F_{\mathrm{s}}}}
$$

where $\partial P_{n} / \partial F_{\mathrm{s}}$ is computed using eq. [17]. To ensure convergence, the increment of $F_{\mathrm{s}}$ must be restricted in a limit. For this purpose, $\max \left|\Delta F_{s}\right| \leq 0.5$ is recommended. The iteration process is terminated if $\left|\Delta F_{s}\right| \leq 0.05$.

The modified value of $F_{\mathrm{s}}$ at the end of this stage and the value of $\lambda$ given by eq. [21] are used as the initial values for the second stage of determining $F_{\mathrm{s}}$ and $\lambda$ simultaneously.

\section{Example 1}

For the purpose of illustration, an example slope as shown in Fig. 2 is analyzed using the procedure proposed in this paper. Two forms of interslice force function commonly used in slope engineering are chosen: one is a constant shape and the other is of half-sine shape. One hundred vertical slices are used to discretize the sliding mass. The results obtained with this iteration process are presented in Table 1. The solutions have converged rapidly and with rather high precision, although such precision is not always necessary for routine analysis.
Table 2. Soil properties used in example 2.

\begin{tabular}{llcl}
\hline Layer & $\gamma\left(\mathrm{kN} / \mathrm{m}^{3}\right)$ & $c^{\prime}(\mathrm{kPa})$ & $\phi^{\prime}\left({ }^{\circ}\right)$ \\
\hline 1 & 19.0 & 0.0 & 26.0 \\
2 & 18.8 & 21.5 & 20.0 \\
3 & 18.0 & 15.5 & 26.0 \\
4 & 18.5 & 28.0 & 22.0 \\
5 & 19.0 & 50.0 & 10.0 \\
\hline
\end{tabular}

\section{Example 2}

Another slope with complex soil stratigraphy and water table is analyzed as shown in Fig. 3. The soil properties are given in Table 2. A horizontal seismic coefficient of 0.1 is adopted and the sliding mass is divided into 100 vertical slices. The results are presented in Table 3. For benchmarking purposes, the Slope/W computer software (Geo-Slope International Ltd. 1998) is also used to calculate the factor of safety of the slope in this example. Four loading cases are considered: water pressure and earthquake; water pressure and no earthquake; earthquake and no water pressure; and absence of both water pressure and earthquake. A comparison of the factor of safety values and the associated scaling factors computed with the method proposed in this paper and with the Slope/W software is presented in Table 4. The differences in computed values of factor of safety are negligible for practical purposes and the associated values of scaling factor given by the two methods are nearly identical.

\section{Concluding remarks}

The formulation of the Morgenstern-Price method and the computation procedure presented in this paper are relatively straightforward compared with those of other approaches suggested previously. Equations $[7 a]$ and $[7 b]$ are the basic equations involving the two unknowns $\lambda$ and $F_{\mathrm{s}}$. The terms on the left-hand sides of eqs. $[7 a]$ and $[7 b]$ can be calculated using the recurrence relations, i.e., eqs. [3] and [6]. The Newton-Raphson method is used for solving eqs. [7a] and $[7 b]$. The required derivatives are given by eqs. [17]-[20]. Reasonable initial values of $\lambda$ and $F_{\mathrm{s}}$ can be deduced from eqs. [21] and [22]. 
Fig. 3. Slope used in example 2.

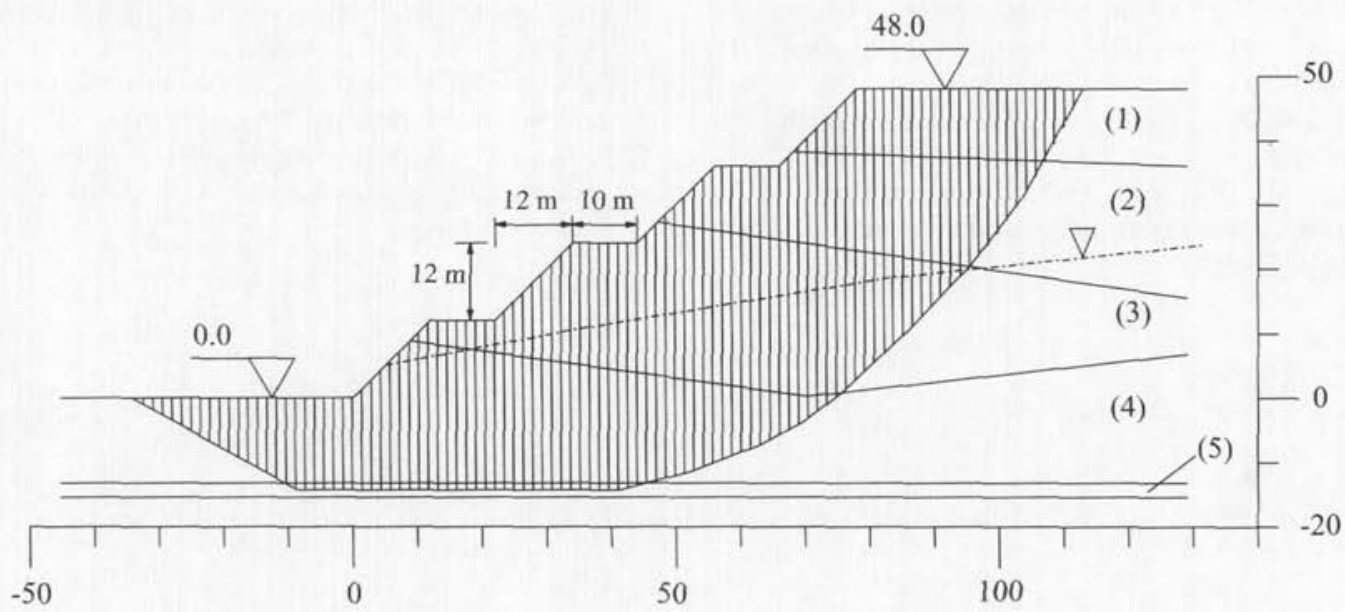

Table 3. Iteration process for computing the factor of safety in example 2 .

\begin{tabular}{|c|c|c|c|c|c|c|c|c|c|}
\hline \multicolumn{5}{|c|}{$f\left(x^{\prime}\right)=1$} & \multicolumn{5}{|c|}{$f\left(x^{\prime}\right)=\sin \left(x^{\prime}\right)$} \\
\hline$F_{\mathrm{s}}$ & $\lambda$ & $P_{n}(\mathrm{kN})$ & $\Delta F_{\mathrm{s}}$ & $M_{n}(\mathrm{kN} \cdot \mathrm{m})$ & $F_{\mathrm{s}}$ & $\lambda$ & $P_{n}(\mathrm{kN})$ & $\Delta F_{\mathrm{s}}$ & $M_{n}(\mathrm{kN} \cdot \mathrm{m})$ \\
\hline \multicolumn{10}{|c|}{ Compute initial value of $F_{\mathrm{s}}$} \\
\hline 1.0000 & 0.2282 & 7226.5 & -0.2911 & & 1.0000 & 0.2282 & 6674.4 & -0.3325 & \\
\hline 0.7089 & 0.2282 & -3196.8 & 0.0602 & & 0.6675 & 0.2282 & -2625.4 & 0.0667 & \\
\hline 0.7692 & 0.2282 & -296.3 & 0.0068 & & 0.7341 & 0.2282 & -180.7 & 0.0053 & \\
\hline \multicolumn{10}{|c|}{ Compute converged values of $F_{s}$ and $\lambda$} \\
\hline 0.7760 & 0.2282 & -3.3 & & -116895.6 & 0.7395 & 0.2282 & -0.8 & & -173891.6 \\
\hline 0.8916 & 0.3369 & 2345.6 & & 56445.6 & 0.8978 & 0.5022 & 2008.8 & & 118147.5 \\
\hline 0.8348 & 0.3294 & -304.9 & & -2858.2 & 0.8133 & 0.4649 & 435.4 & & 29457.7 \\
\hline 0.8283 & 0.3274 & -23.9 & & -295.4 & 0.7953 & 0.4501 & 95.6 & & 5505.7 \\
\hline 0.8266 & 0.3273 & -1.2 & & -12.4 & 0.7913 & 0.4475 & 11.8 & & 632.3 \\
\hline \multirow[t]{2}{*}{0.8265} & 0.3273 & -0.07 & & -0.7 & 0.7908 & 0.4472 & 1.2 & & 61.2 \\
\hline & & & & & 0.7907 & 0.4472 & 0.1 & & 5.4 \\
\hline
\end{tabular}

Table 4. Comparison of calculated factors of safety.

\begin{tabular}{|c|c|c|c|c|c|c|}
\hline \multirow{2}{*}{$\begin{array}{l}\text { Water } \\
\text { pressure }\end{array}$} & \multirow{2}{*}{$\begin{array}{l}\text { Earthquake } \\
\text { effect }\end{array}$} & \multicolumn{2}{|c|}{$f\left(x^{\prime}\right)=1$} & \multicolumn{2}{|c|}{$f\left(x^{\prime}\right)=\sin \left(x^{\prime}\right)$} & \multirow[b]{2}{*}{ Procedure } \\
\hline & & $F_{\mathrm{s}}$ & $\lambda$ & $F_{\mathrm{s}}$ & $\lambda$ & \\
\hline \multirow[t]{2}{*}{ Yes } & \multirow[t]{2}{*}{ Yes } & 0.827 & 0.3273 & 0.791 & 0.4472 & Present study \\
\hline & & 0.834 & 0.3278 & 0.798 & 0.4479 & Seep/W \\
\hline \multirow[t]{2}{*}{ Yes } & \multirow[t]{2}{*}{ No } & 1.023 & 0.2512 & 1.000 & 0.3307 & Present study \\
\hline & & 1.032 & 0.2518 & 1.008 & 0.3315 & Seep/W \\
\hline \multirow[t]{2}{*}{ No } & \multirow[t]{2}{*}{ Yes } & 1.081 & 0.3526 & 1.045 & 0.4800 & Present study \\
\hline & & 1.084 & 0.3522 & 1.048 & 0.4797 & Seep/W \\
\hline \multirow[t]{2}{*}{ No } & \multirow[t]{2}{*}{ No } & 1.341 & 0.2707 & 1.316 & 0.3591 & Present study \\
\hline & & 1.345 & 0.2703 & 1.320 & 0.3587 & Seep/W \\
\hline
\end{tabular}

Since all equations are of a closed-form nature, accuracy is adequately ensured. Furthermore, the proposed approach can be easily implemented into a computer program because all the expressions entering into the computation process are in algebraic form.

\section{References}

Chen, Z., and Morgenstern, N.R. 1983. Extensions to the generalized method of slices for stability analysis. Canadian Geotechnical Journal, 20: 104-1 19.
Duncan, J.M. 1996. State of the art: limit equilibrium and finiteelement analysis of slopes. Journal of Geotechnical Engineering, ASCE, 122(7): 577-596.

Fredlund, D.G., and Krahn, J. 1977. Comparison of slope stability methods of analysis. Canadian Geotechnical Journal, 14: 429-439.

Geo-Slope International Ltd. 1998. Slope/W for slope stability analysis, user's guide, version 4. Geo-Slope International Ltd., Calgary, Alta.

Janbu, N., Bjerrum, L., and Kjaernsli, B. 1956. Soil mechanics applied to some engineering problems. Norwegian Geotechnical Institute Publication 16. 
Lowe, J., and Karafiath, L. 1960. Stability of earth dams upon drawdown. In Proceedings of the 1st Pan-American Conference on Soil Mechanics and Foundation Engineering, Mexico City, Vol. 2, pp. 537-552.

Morgenstern, N.R., and Price, V.E. 1965. The analysis of the stability of general slip surfaces. Géotechnique, 15(1): 79-93.

Morgenstern, N.R., and Price, V.E. 1967. A numerical method for solving the equations of stability of general slip surfaces. Computer Journal, 9: 388-393.
Spencer, E. 1967. A method of analysis of the stability of embankments assuming parallel interslice forces. Géotechnique, 17(1): $11-26$.

Spencer, E. 1973. The thrust line criterion in embankment stability analysis. Géotechnique, 23(1): 85-100.

U.S. Army Corps of Engineers. 1967. Stability of slopes and foundations. Engineering manual. U.S. Army Corps of Engineers, Vicksburg, Miss. 